\title{
Fine metabolic regulation in ruminants via nutrient-gene interactions: saturated long-chain fatty acids increase expression of genes involved in lipid metabolism and immune response partly through PPAR- $\alpha$ activation
}

\author{
Massimo Bionaz†, Betsy J. Theringt and Juan J. Loor* \\ Mammalian NutriPhysioGenomics, Division of Nutritional Sciences, 498 Animal Sciences Laboratory, Department of \\ Animal Sciences, University of Illinois, Urbana, IL 61801, USA
}

(Received 15 December 2010 - Revised 30 March 2011 - Accepted 12 April 2011 - First published online 6 July 2011)

\begin{abstract}
Madin-Darby Bovine Kidney cells cultured with $150 \mu \mathrm{M}$ of Wy-14643 (WY, PPAR $\alpha$ agonist) or twelve long-chain fatty acids (LCFA; 16:0, 18:0, cis-9-18:1, trans-10-18:1, trans-11-18:1, 18:2n-6, 18:3n-3, cis-9, trans-11-18:2, trans-10, cis-12-18:2, 20:0, 20:5n-3 and $22: 6 n-3)$ were used to uncover PPAR- $\alpha$ target genes and determine the effects of LCFA on expression of thirty genes with key functions in lipid metabolism and inflammation. Among fifteen known PPAR- $\alpha$ targets in non-ruminants, ten had greater expression with WY, suggesting that they are bovine PPAR- $\alpha$ targets. The expression of SPP1 and LPIN3 was increased by WY, with no evidence of a similar effect in the published literature, suggesting that both represent bovine-specific PPAR- $\alpha$ targets. We observed the strongest effect on the expression of PPAR- $\alpha$ targets with 16:0,18:0 and 20:5n-3. When considering the overall effect on expression of the thirty selected genes $20: 5 n-3,16: 0$ and $18: 0$ had the greatest effect followed by $20: 0$ and $c 9 t 11-18: 2$. Gene network analysis indicated an overall increase in lipid metabolism by WY and all LCFA with a central role of PPAR- $\alpha$ but also additional putative transcription factors. A greater increase in the expression of inflammatory genes was observed with $16: 0$ and $18: 0$. Among LCFA, 20:5n-3, 16:0 and 18:0 were the most potent PPAR- $\alpha$ agonists. They also affected the expression of non-PPAR- $\alpha$ targets, eliciting an overall increase in the expression of genes related to lipid metabolism, signalling and inflammatory response. Data appear to highlight a teleological evolutionary adaptation of PPAR in ruminants to cope with the greater availability of saturated rather than unsaturated LCFA.
\end{abstract}

Key words: Transcriptomics: Ruminants: Liver: PPAR response element

PPAR- $\alpha$, PPAR- $\gamma$ and PPAR- $\beta / \delta$, which are a sub-class of the nuclear hormone receptor superfamily, represent potential molecular targets to prevent metabolic disorders associated with lipid metabolism, glucose metabolism (particularly PPAR- $\gamma$ ) and immune function (i.e. have anti-inflammatory potential) ${ }^{(1)}$. In non-ruminants, and particularly in rodents, PPAR- $\alpha$ is highly expressed in the liver and has a pivotal role in increasing the oxidation of long-chain fatty acids $(\mathrm{LCFA})^{(2,3)}$. A beneficial role of PPAR- $\alpha$ in reducing fatty liver and overall liver inflammatory response has been demonstrated in mice ${ }^{(4-6)}$.

From a practical standpoint, the prevention of fatty liver in peripartal dairy cows, with the associated metabolic issues (e.g. ketosis), is without doubt a priority in order to prevent impairment in performance ${ }^{(7)}$. Fatty liver in peripartal cows is caused by the surge of NEFA as a consequence of a marked negative energy balance ${ }^{(7)}$. Based on the data on rodents, it has been proposed ${ }^{(7)}$ that activation of PPAR- $\alpha$ could improve the overall capacity of the peripartal bovine liver to oxidise LCFA, thus preventing fatty liver. Except for few preliminary data ${ }^{(8-12)}$ there is a lack of information available on the regulation of PPAR activity in ruminant cells or tissues.

The activity of PPAR in non-ruminants is modulated by LCFA. The potency of inducing transcription through PPAR activation varies among the types of $\mathrm{LCFA}^{(1)}$ and it is dose-dependent ${ }^{(13)}$. Other than preliminary evidence of an effect of LCFA on ruminant PPAR activation ${ }^{(10,11)}$, the

Abbreviations: ACOX1, acyl-coenzyme A oxidase 1; CD36, CD36 molecule; CLA, conjugated linoleic acid; CPT1A, carnitine palmitoyltransferase 1A; CTR, control; FABP3, fatty acid binding protein 3; HMGCR, 3-hydroxy-3-methylglutaryl-coenzyme A reductase; HP, haptoglobin; LCFA, long-chain fatty acid; LPIN1, lipin 1; MDBK, Madin-Darby Bovine Kidney cell; PPRE, PPAR response element; qPCR, quantitative real-time RT-PCR; SCD, stearoyl CoA desaturase; SREBF1, sterol regulatory element binding transcription factor 1; WY, Wy-14643.

* Corresponding author: Dr J. J. Loor, fax +1 217333 8286, email jloor@illinois.edu

†These authors contributed equally. 
transcriptomics effects associated with specific LCFA, both dietary and rumen-derived saturated and unsaturated, remain relatively unknown.

The specific objectives of the present study were to (1) find reliable bovine PPAR- $\alpha$ targets among key metabolic genes (mostly established PPAR- $\alpha$ target genes in non-ruminants) after treatment with Wy-14643 (WY; a potent specific PPAR- $\alpha$ agonist in bovine endothelial cells $\left.{ }^{(14,15)}\right)$; (2) test the effect of several LCFA on PPAR- $\alpha$ activation by measuring the expression of the bovine-specific PPAR- $\alpha$ genes and (3) investigate LCFA-specific effects, besides PPAR- $\alpha$ activation, on networks among the genes measured.

\section{Materials and methods}

\section{Fatty acid preparation, cell culture and treatments}

Treatments included WY (270-198-M010, Alexis Biochemicals, Lausen, Switzerland), palmitic acid (16:0; N-16-A, Nu-Chek Prep, Inc., Elysian, MN, USA), stearic acid (18:0; N-18-A, Nu-Chek Prep, Inc.), oleic acid (cis9-18: 1; 1022, Matreya, Pleasant Gap, PA, USA), trans10-18:1 (provided by Dr R. A. Erdman, University of Maryland, College Park, MD, USA), vaccenic acid (trans11-18:1; U-49-A, Nu-Chek Prep, Inc.), linoleic acid (18:2; 215040050, Acros Organics, Morris Plains, NJ, USA), rumenic acid ( $c 9, t 11$ CLA; no. 1245, Matreya), trans10, cis12-18:2 (t10, c12CLA; no. 1249, Matreya), $\alpha$-linolenic acid (18:3; no. 302820010, Acros Organics), phytanic acid (20: 0; no. 1195, Matreya), EPA (20:5n-3; no. N-20-A, NuChek Prep, Inc.) and DHA (22:6n-3, no. 90310, Cayman Chemical Company, Ann Arbor, MI, USA). Fatty acids were saponified using an equimolar concentration of $\mathrm{NaOH}$ and dissolved in a final solution of $95 \%$ ethanol to obtain a stock concentration of $30 \mathrm{~mm}$. WY was dissolved in 95\% ethanol.

Preliminary data demonstrated that Madin-Darby Bovine kidney cells (MDBK) are a suitable in vitro model to test PPAR activation ${ }^{(10,11)}$. The MDBK cells were obtained from ATCC (CCL-22, Manassas, VA, USA) at passage 110. A previous investigation was conducted to characterise them and to set optimal conditions for the present study ${ }^{(11)}$. The results from the previous investigation indicated $6 \mathrm{~h}$ of incubation, use of LCFA not bound to albumin and addition of insulin to the culture were the best conditions to measure maximal expression of most genes of interest. Based on another preliminary study ${ }^{(10)}$, the present study was performed using $150 \mu \mathrm{m}$ each of LCFA and WY in order to directly compare the potency in the activation of gene expression among treatments. All treatments were administered in $\mathrm{HyQ}^{\circledR}$ Minimum Essential Media/Earle's Balanced Salts (MEM/EBSS; no. SH30024.02, HyClone, Logan, UT, USA) without fetal bovine serum and containing bovine insulin $(5 \mathrm{mg} / \mathrm{l}$; no. 1882, Sigma, St Louis, MO, USA). In addition, an ethanol control (CTR) to account for the ethanol effect $(5 \mathrm{ml} / \mathrm{l})$ and only media were run. All treatments were run in triplicate. After $6 \mathrm{~h}$ incubation the cells were harvested in $1 \mathrm{ml}$ TRIzol ${ }^{\circledR}$ reagent (Invitrogen, Carlsbad, CA, USA) and immediately stored at $-80^{\circ} \mathrm{C}$ until RNA extraction.

\section{Transcripts measured}

The description, main function(s) and sub-cellular location of the products of the genes of interest are reported in Table S1 (additional file 1, available online at http://www.journals. cambridge.org/bin). Those genes were chosen partly because of their potential as targets of PPAR- $\alpha$ in non-ruminant species, as highlighted by Fig. S1 (additional file 1, available online at http:// www.journals.cambridge.org/bjn) and based on key functions in LCFA uptake and trafficking (e.g. CD36 molecule (CD36), fatty acid binding protein 3 (FABP3)), LCFA oxidation (e.g. acyl-coenzyme A oxidase 1 ( $A C O X 1)$, carnitine palmitoyltransferase $1 \mathrm{~A}$ $(C P T 1 A)$ ), TAG synthesis (e.g. stearoyl-CoA desaturase (SCD), lipin 1 (LPIN1)), cholesterol synthesis (e.g. 3-hydroxy-3-methylglutaryl-coenzyme A reductase $(H M G C R)$ ), gene transcription (e.g. sterol regulatory element binding transcription factor 1 $(S R E B F 1)$ ), gluconeogenesis (pyruvate carboxylase $(P C)$ ) and immune response (including acute-phase reaction) (e.g. ILG, haptoglobin $(H P)$ ). We also characterised the response to LCFA of isoforms of novel genes, which have been demonstrated to be crucial in bovine mammary TAG synthesis ${ }^{(16)}$ and are targets ${ }^{(17)}$ or co-activators ${ }^{(18,19)}$ of non-ruminant PPAR $\alpha$ (acyl-CoA synthetase long-chain family member and lipin isoforms, respectively).

\section{Additional materials and methods}

The details of RNA extraction and quantitative real-time RT-PCR (qPCR), relative mRNA abundance between measured transcripts, network development using Ingenuity Pathway Analysis ${ }^{\circledR}$ (Ingenuity Systems Inc., Redwood City, CA, USA) and hierarchical clustering among genes and treatments are reported in additional file 1 (supplementary material available online http://www. journals.cambridge.org/bjn). qPCR performance and primer features are reported in Tables S2 and S3 (additional file 1, available online at http://www.journals.cambridge.org/bjn).

\section{Minimum Information for publication of Quantitative real-time PCR Experiments (MIQE) compliance of quantitative real-time $R T-P C R$ data}

The qPCR data with all available information have been submitted as an Real-time PCR Data Markup Language $(\mathrm{RDML})^{(20)}$ file and, except for RNA integrity, all the other information required by the MIQE guideline ${ }^{(21)}$ are provided in the main paper or in additional file 1 (supplementary material available online at http://www.journals.cambridge.org/bjn).

\section{Statistical analysis}

qPCR-normalised data are presented as $\log _{2}$-transformed foldchange relative to CTR. In earlier statistical analysis all data were transformed as fold-change relative to CTR and $\log _{2}$ transformed to normalise the data, to minimise the effects of the outliers and to prevent a bias towards the treatments with extremely large effects. The presence of possible outliers was assessed by PROC REG of SAS (SAS Institute Inc., Cary, NC, USA, release 9.0) on $\log _{2}$-transformed data and data points with studentised residuals $\geq 2.5$ were considered 
outliers and excluded from the analysis. This final data set was analysed using a generalised linear model (GLM). Treatment was considered as a fixed effect and replicate as a random effect. The multiple comparisons were corrected using Tukey's test. Significance was declared at $P$-corrected $\leq 0.05$ for all comparisons. Pearson's correlation analysis was run using the PROC CORR procedure of SAS.

\section{Peroxisome proliferator-activated receptor response element and three-dimensional structure modelling analyses}

In order to uncover the potential PPAR response element (PPRE) in the sequence (promoter + coding sequence) of the measured genes we used the software RESearch ${ }^{(22)}$. To evaluate the similarity of three-dimensional structure of PPAR- $\alpha$ between species and between PPAR isotypes we used the Swiss-Pdb Viewer ${ }^{(23)}$. Both methodologies are described in detail in additional file 1 (supplementary material available online at http://www. journals.cambridge.org/bjn).

\section{Results and discussion}

\section{Bovine PPAR- $\alpha$ target genes}

Among several methods available to assess the activity of PPAR- $\alpha$, e.g. through firefly luciferase reporter, the use of well-established agonists is a reliable and easy, albeit indirect, alternative. In all mammalian cells tested to date ${ }^{(24)}$, including bovine ${ }^{(14,15)}$, WY has been demonstrated to be a potent PPAR- $\alpha$ activator and a weak PPAR- $\gamma$ activator ${ }^{(25)}$. We used WY as positive CTR in the present study.

Figs. S1 and S2 (additional file 1, available online at http:// www.journals.cambridge.org/bjn) report the percentage of abundance among the measured genes and the known networks among all the genes measured. The networks generated using both the Ingenuity Pathway Analysis Knowledge Base and previous reports ${ }^{(26-28)}$ encompass fifteen out of thirty genes measured in the present study, whose expression has been demonstrated to be specifically under control of PPAR- $\alpha$ (i.e. these are downstream PPAR- $\alpha$ target genes). Among the fifteen known PPAR- $\alpha$ target genes in the non-ruminants that we tested, nine genes including ACSL1, ACSL3, ANGPTL4, CD36, CPT1A, FABP4, LPIN1, SCD and SREBF1 were significantly up-regulated by treatment with WY (Figs. 1 and 2 and summary in Fig. 3) confirming they also are PPAR- $\alpha$ targets in bovines (bold arrows in Fig. 3). Among the remaining PPAR- $\alpha$ target genes reported in non-ruminants, FABP3,DBI, ACOX1 and $U C P 2$ were not significantly affected by WY and HMGCS1 had only a numerical increase in expression (Fig. 3). In addition, in non-ruminants, PPAR- $\alpha$ controls the expression of its own gene (i.e. $P P A R A)^{(26,29)}$. Our data clearly indicated that $6 \mathrm{~h}$ incubation with WY did not affect PPARA expression (Fig. 2). These data support previous results from a $24 \mathrm{~h}$ time-course experiment using MDBK cells ${ }^{(11)}$. Expression of SPP1 and LPIN3 appeared to be induced by WY (Table 1 and Fig. 2) but they have not been previously reported to be PPAR- $\alpha$ targets; thus, they can be considered putative bovine-specific PPAR- $\alpha$ targets (dashed lines in Fig. 3).
Among the fifteen known PPAR- $\alpha$ target genes in nonruminants (Fig. 3), ten (approximately 67\%) were confirmed to be PPAR- $\alpha$ target genes in MDBK cells. A comparison with other studies where hepatocytes from mice, humans or rats were treated with $\mathrm{WY}^{(24,27)}$ (see additional file 1 for detailed discussion, supplementary material for this article can be found at http://www.journals.cambridge.org/bjn) revealed some overlap in response but a greater sensitivity of MDBK to WY compared with non-ruminant hepatocytes. Ligand-induced activation of PPAR- $\alpha$ in non-ruminants, especially in rodents, leads to altered expression of many genes associated with fatty acid oxidation as well as other liver-specific functions ${ }^{(3,24,26)}$. In this regard, besides the lack in response of $A C O X 1$, our data in MDBK suggest a potential increase in the capacity for LCFA oxidation through greater LCFA entry and transport into cytoplasm $(\Uparrow C D 36, \Uparrow F A B P 4$ and $\Uparrow A C S L 1$ ) as well as mitochondria ( $\Uparrow C P T 1 A$; Figs. 1 and 3), all data that appear to support the findings in nonruminants. In addition, our data suggest that some of the steps leading to the synthesis of TAG and cholesterol are under the control of PPAR- $\alpha$ (Fig. 3). The control of the expression of the genes related to desaturation, as well of LPIN1 ${ }^{(30)}$, by PPAR- $\alpha$ in mouse liver has been reported previously $^{(26,31)}$, but there are no reports, to our knowledge, of an increased amount of intra- or extra-cellular quantity of TAG via the activation of PPAR- $\alpha$. We recognise that the increase in the expression of one or few genes in a pathway would probably not increase the total metabolic flux, as discussed previously ${ }^{(16,32)}$. However, the induction of lipogenesis as a consequence of PPAR- $\alpha$ activation seems more supported by the increase in SREBF1 expression, which is a wellestablished regulator of lipid synthesis in non-ruminants (particularly de novo LCFA synthesis) ${ }^{(33)}$. The increase in expression of this gene after treatment with WY also has been observed in mouse and human hepatocytes ${ }^{(24,28)}$. The biological meaning of this is not apparent, but reinforces previous findings from our laboratory using bovine mammary cells, where it was evident that activation of PPAR $\gamma$ after $6 \mathrm{~h}$ of treatment with rosiglitazone increased SREBF1 expression approximately twofold ${ }^{(34)}$. Overall, it appears that bovine $S R E B F 1$ is under control of PPAR isotypes. We cannot exclude that the increase in expression of SREBF1 in the present study was due to a partial activation of PPAR $\gamma$ by $\mathrm{WY}^{(25)}$. However, recent data in HepG2 cells appear to support the idea that PPAR $\alpha$ through cross-talk with SREBP signalling ${ }^{(28)}$ controls lipid and cholesterol synthesis.

To evaluate a potential relationship between PPRE and genes responsive to WY, we conducted an in silico analysis that provided number, location and strength of PPRE in the sequence of all measured genes ${ }^{(22)}$. The analysis of PPRE (see Tables S6 and S7, Figs. S3 and S4 and relative results and discussion in additional file 1 , supplementary material for this article can be found at http://www.journals. cambridge.org/bjn) provided some support for the gene expression data as reflected by the fact that we found a greater percentage of medium-strong PPRE in genes affected by WY compared with the non-WY-sensitive genes (additional files 2 and 3, supplementary material for this article can be found 

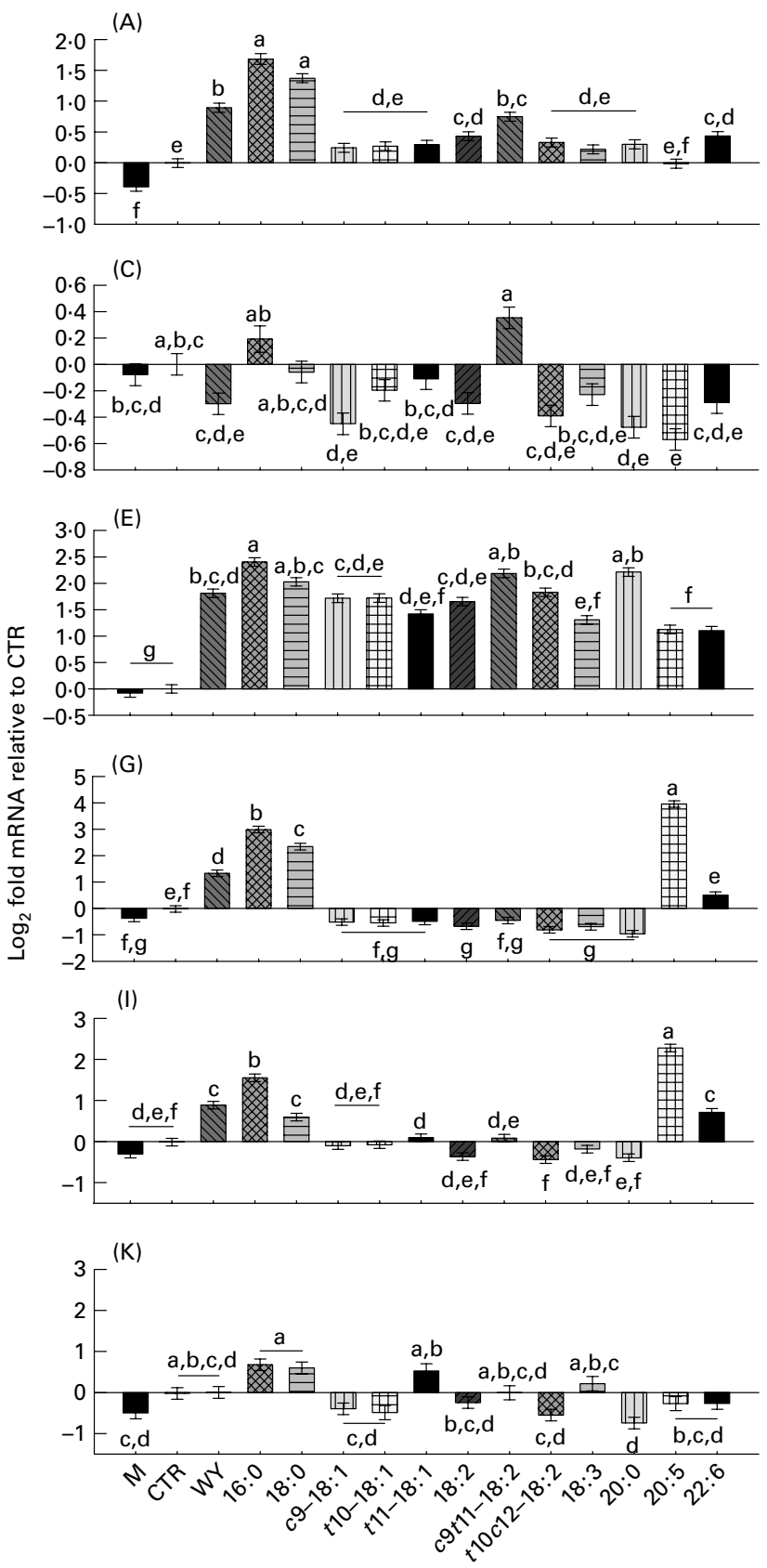
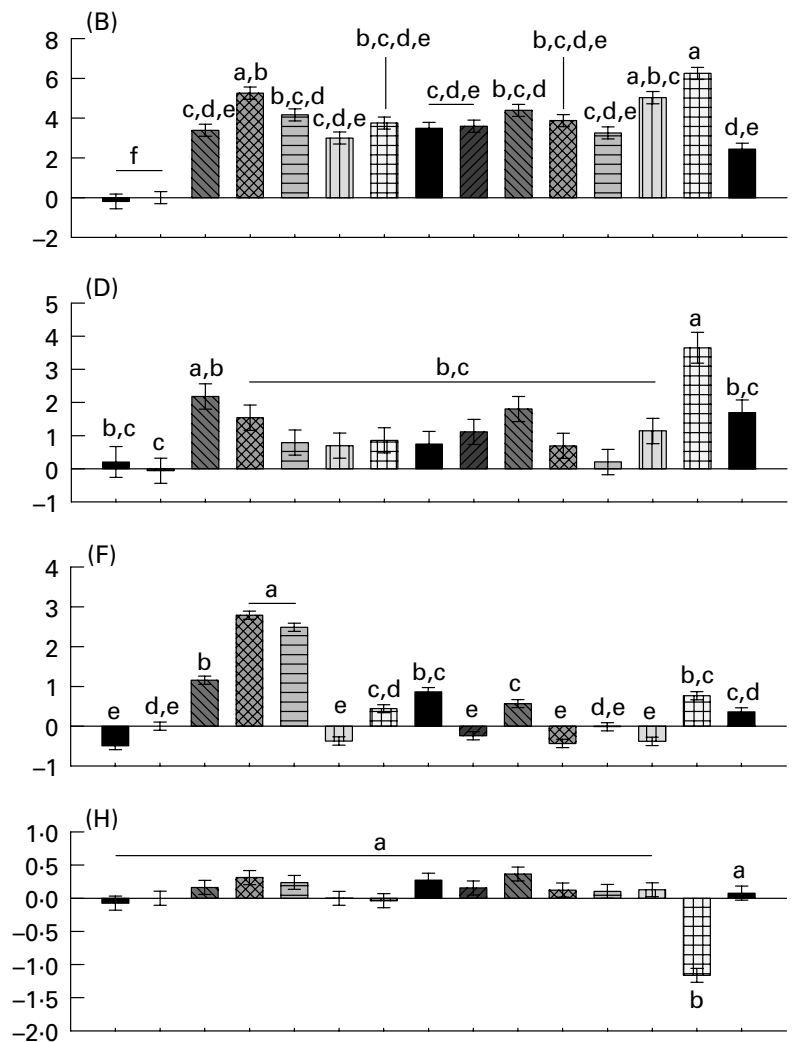

(J)
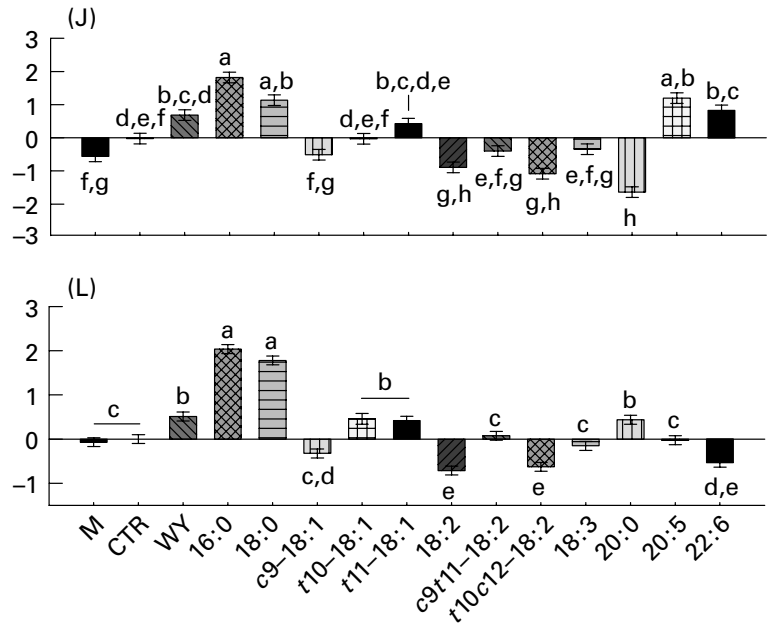

Treatments

Fig. 1. Effect of $150 \mu \mathrm{M}$ of $\mathrm{Wy}-14643$ (WY) or several long-chain fatty acid (LCFA) treatments for $6 \mathrm{~h}$ on the expression of selected genes related to lipid metabolism. Mean values with unlike letters were significantly different $(P<0.05$; Tukey's corrected). (A) $A C S L 1$, acyl-coenzyme A synthetase long-chain family member 1; (B) $C D 36$, fatty acid translocase CD36 molecule (thrombospondin receptor); (C) FABP3, fatty acid-binding protein 3; (D) FABP4, fatty acid-binding protein 4; (E) CPT1A, carnitine palmitoyltransferase $1 \mathrm{~A}$; (F) SCD, stearoyl-coenzyme A desaturase; (G) LPIN1, lipin 1; (H) DGAT1, diacylglycerol-O-acyltransferase homolog 1; (I) HMGCR, 3-hydroxy-3-methylglutaryl-coenzyme A reductase; (J) HMGCS1, 3-hydroxy-3-methylglutaryl-coenzyme A synthase 1 (soluble); (K) SREBF2, sterol regulatory element-binding transcription factor 2; (L) SREBF1, sterol regulatory element-binding transcription factor 1. M, media; CTR, control (ethanol).

at http://www.journals.cambridge.org/bjn). However, the in silico approach for the prediction of PPAR target genes in bovines appears to be weak. The system used to evaluate the PPRE in the selected genes was developed for nonruminants $^{(22)}$ and a difference in PPRE response between non-ruminant species has been demonstrated for $\operatorname{ACOX} 1^{(35,36)}$. An interesting outcome from the PPRE analysis was the finding of a PPRE in bovine SPP1. This gene has not been reported to be a PPAR- $\alpha$ target in non-ruminants but, rather, its expression is down-regulated by the activation of both PPAR- $\alpha^{(37)}$ and PPAR- $\gamma^{(38)}$. However, those results were not confirmed by transcriptomics analysis in mice, humans ${ }^{(24)}$ or rats ${ }^{(27)}$, where SPP1 expression was unchanged after WY treatment. PPRE analysis in bovines clearly showed that this gene presents, uniquely among all measured genes, only two medium-strength PPRE for PPAR- $\alpha$ located far up-stream relative to the transcription start site (probably considered distal) but none, except a weak PPRE, for the other 
PPAR signalling and glucose synthesis
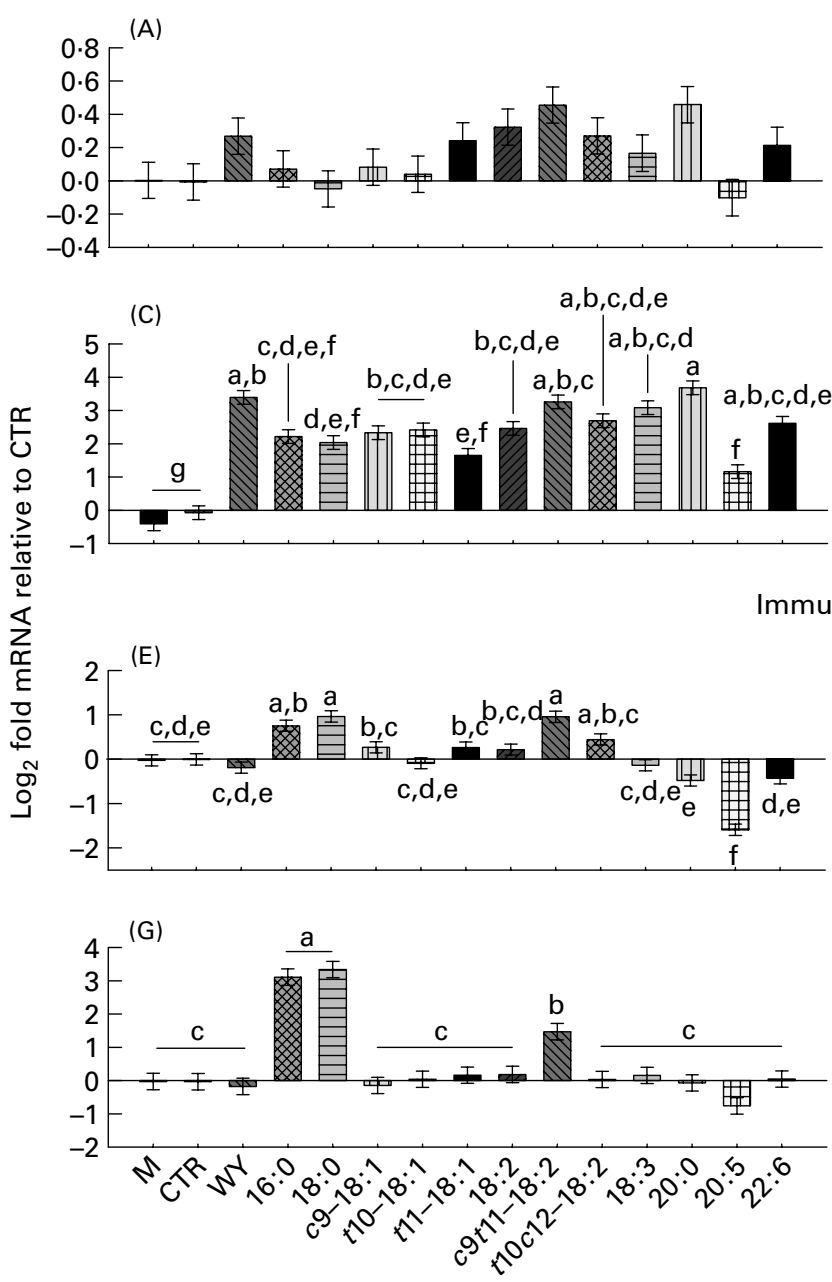

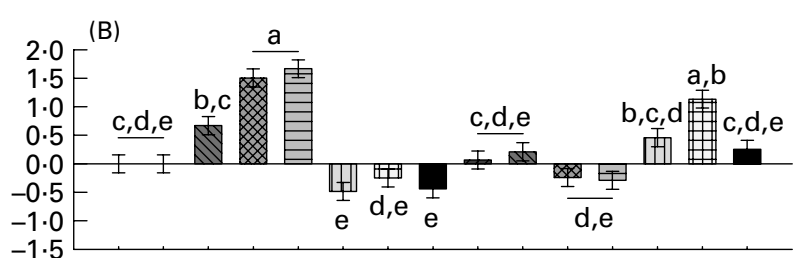

(D)

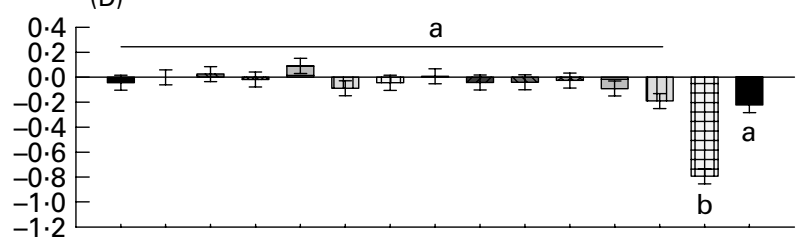

Fig. 2. Effect of $150 \mu \mathrm{M}$ of Wy-14643 (WY) or several long-chain fatty acid (LCFA) treatments for $6 \mathrm{~h}$ on the expression of selected genes related to PPAR $\alpha$ signalling and immune response. Mean values with unlike letters were significantly different $(P<0.05$; Tukey's corrected). (A) PPARA, PPAR alpha; (B) PPARGC1A, PPAR gamma coactivator 1- $\alpha$; (C) ANGPTL4, angiopoietin-like 4; (D) PC, pyruvate carboxylase; (E) IL6; (F) HP, haptoglobin; (G) SAA3, serum amyloid A 3; (H) SPP1, secreted phosphoprotein 1. M, media; CTR, control (ethanol).

two PPAR isotypes (Fig. S3 in additional file 1, supplementary material for this article can be found at http://www.journals. cambridge.org/bjn). Together, with the gene expression results (Fig. 2), these data strongly support the notion that bovine SPP1 is a specific target gene of PPAR- $\alpha$ in bovines.

We conducted an alignment and three-dimensional structure analyses of the PPAR- $\alpha$ proteins with the purpose of evaluating the potential differences in PPAR- $\alpha$ response to WY observed between the species (see above). The conservation of amino acid sequence of PPAR- $\alpha$ proteins between mice, humans and bovines is $>90 \%$, with $100 \%$ conservation in the DNA-binding domain, which interacts with the PPRE (Table S8 in the additional file 1 , supplementary material for this article can be found at http://www.journals.cambridge.org/bjn). The remarkable degree of homology at the protein level is indicative of a high degree of functional conservation, which in turn suggests that bovine PPAR- $\alpha$ should be able to bind to non-ruminant PPRE. This has been clearly demonstrated by the successful activation of a luciferase construct with rat acyl-CoA oxidase PPRE in bovine cells ${ }^{(39)}$. The sequence homology of the ligand-binding domain, which constitutes the pocket for the entry and binding of agonists, is $>90 \%$ conserved between the three species, with almost $98 \%$ conservation between bovines and humans (Table S8.2 in additional file 1, supplementary material for this article can be found at http://www.journals.cambridge.org/ bjn), but the differences observed with the three-dimensional protein structure of the ligand-binding domain (Figs. S5-S9 and related results and discussion in additional file 1, supplementary material for this article can be found at http:// www.journals.cambridge.org/bjn) appear to shed some light on the varying response of mice and bovines to PPAR- $\alpha$ agonists despite the high degree of conservation of the primary structure. The data indicated a larger and more neutral ligand pocket in bovine compared with mouse PPAR- $\alpha$. Detailed molecular analyses will have to be performed to determine the specific consequences of the observed differences but might explain the contrast in WY response between species and the poor agreement between the PPRE analysis and our gene expression data. 


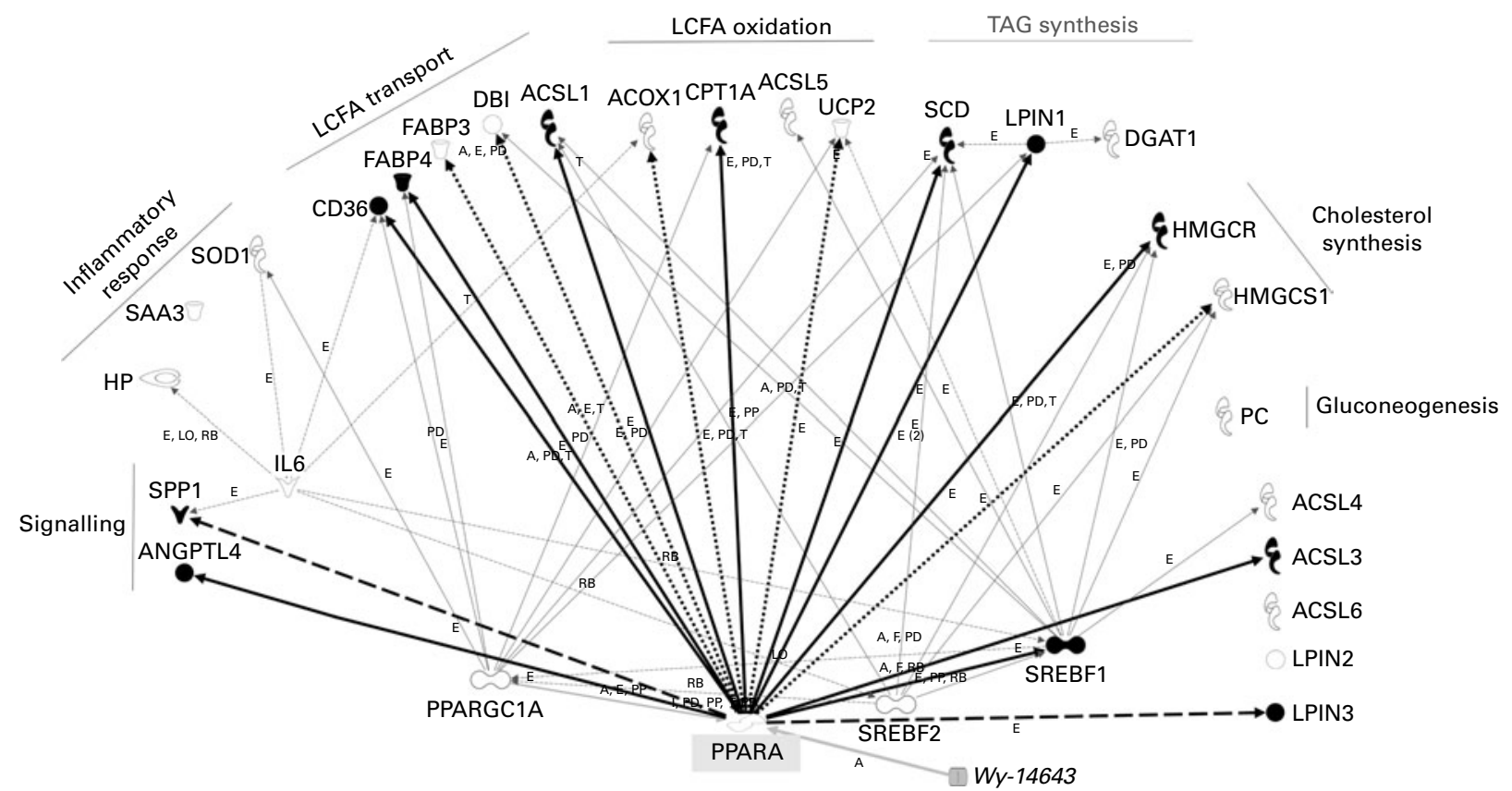

Fig. 3. Networks generated with Ingenuity Pathway Analysis ${ }^{\circledR}$ (IPA) among all genes measured with information from the IPA Knowledge Database (IKB; i.e. all known interactions) (last updated November 2009). The genes are denoted by objects and the letters along the arrows denote the type of effect (activation (A), effects on gene expression (E), protein-protein interactions (PP), protein-DNA interactions (PD), inhibition (I), RNA binding (RB), effect on translation (T) and effect on localisation (LO)). Black shade objects fill denotes up-regulation of the gene with Wy-14 643 treatment relative to control. Genes have been grouped based on main biological function. The bold arrows highlight the downstream targets genes of PPAR $\alpha$ uncovered by using the IKB (ACOX1, ACSL1, ANGPL4, CD36, CPT1A, DBI, FABP3, FABP4, HMGCS1, PPARA, SCD and UCP2) and additional published targets such as ACSL3 and SREBF1 (24), HMGCR ${ }^{(28)}$ and LPIN1 ${ }^{(30)}$, which overlap with results of our analysis after treatment with Wy-14643 for $6 \mathrm{~h}$ (i.e. similar between non-ruminants and bovine). In dotted lines are highlighted the PPAR $\alpha$ target genes uncovered by using the IKB which were not confirmed by our data. In dashed lines are highlighted positive effect of Wy14643 on expression of SPP1 and LPIN3. Those genes were not recognised in IKB or were not previously published to be PPAR $\alpha$ target genes (i.e. novel and bovine-specific PPAR $\alpha$ target genes). The link between PPARA and HMGCS1 uncovered by IPA is actually referring to the link between PPARA and HMGCS2; however, in rat hepatocytes, HMGCS1 appears to be a PPAR $\alpha$ target gene ${ }^{(27)}$. LCFA, long-chain fatty acid; ANGPTL4, angiopoietin-like 4; SPP1, secreted phosphoprotein 1; HP, haptoglobin; $S A A 3$, serum amyloid A 3; SOD1, superoxide dismutase 1; $C D 36, C D 36$ molecule; $F A B P 3$ and 4, fatty acid-binding protein 3 and 4; $D B I$, diazepam binding inhibitor; $A C S L 1$, acyl-coenzyme $A$ synthetase long-chain family member 1; ACOX1, acyl-coenzyme A oxidase 1; CPT1A, carnitine palmitoyltransferase $1 \mathrm{~A} ; A C S L 3,4,5$, and 6, acyl-coenzyme A synthetase long-chain family member 3, 4, 5 and 6; UCP2, uncoupling protein 2; SCD, stearoyl CoA desaturase; LPIN1, 2 and 3, lipin 1, 2 and 3; DGAT1, diacylglycerol-O-acyltransferase homolog 1; HMGCR, 3-hydroxy-3-methylglutaryl-coenzyme A reductase; HMGCS1, 3-hydroxy-3-methylglutaryl-coenzyme A synthase 1; PC, pyruvate carboxylase; SREBF1 and 2, sterol regulatory element binding transcription factor 1 and 2; PPARA, PPAR alpha; PPARGC1A, PPAR gamma coactivator $1-\alpha$.

Table 1. Effect of $150 \mu \mathrm{M}$ treatment with Wy-14643 (WY) or long-chain fatty acids for $6 \mathrm{~h}$ on the expression of genes not reported in Figs. 1 and 2

\begin{tabular}{|c|c|c|c|c|c|c|c|c|c|c|}
\hline & AcOX1 & ACSL3 & ACSL4 & ACSL5 & ACSL6 & $\mathrm{DBI}$ & LPIN2 & LPIN3 & SOD1 & UCP2 \\
\hline Overall $P$ & 0.003 & $<.0001$ & 0.0004 & $<0.0001$ & 0.24 & 0.01 & $<0.0001$ & $<0.0001$ & $<0.0001$ & 0.002 \\
\hline Medium & $-0.08^{\mathrm{b}, \mathrm{c}}$ & $-0.27^{\mathrm{d}, \mathrm{e}, \mathrm{f}}$ & $-0.36^{\mathrm{c}}$ & $-0.11^{a, b, c}$ & -0.04 & 0.03 & $-0.21^{d}$ & $-0.20^{d}$ & $-0.05^{\mathrm{a}, \mathrm{b}, \mathrm{c}, \mathrm{d}}$ & $0.02^{a, b}$ \\
\hline CTR & $-0.00^{a, b, c}$ & $-0.00^{e, d}$ & $-0.00^{a, b, c}$ & $0.00^{a, b}$ & -0.00 & -0.00 & $0.00^{c, d}$ & $0.00^{c, d}$ & $0.00^{a, b, c, d}$ & $-0.00^{\mathrm{a}, \mathrm{b}}$ \\
\hline WY & $0.07^{a, b, c}$ & $0.74^{b, c}$ & $0.07^{\mathrm{a}, \mathrm{b}, \mathrm{c}}$ & $-0.05^{\mathrm{a}, \mathrm{b}, \mathrm{c}}$ & -0.01 & 0.08 & $0.37^{\mathrm{b}, \mathrm{c}}$ & $0.59^{a, b}$ & $0.13^{\mathrm{a}}$ & $0.13^{\mathrm{a}, \mathrm{b}}$ \\
\hline $16: 0$ & $0.47^{a}$ & $1.95^{\mathrm{a}}$ & $0.69^{a}$ & $-0 \cdot 10^{\mathrm{a}, \mathrm{b}, \mathrm{c}}$ & 0.28 & 0.05 & $0.92^{\mathrm{a}}$ & $0.58^{a, b}$ & $-0.05^{\mathrm{a}, \mathrm{b}, \mathrm{c}, \mathrm{d}}$ & $-0 \cdot 10^{\mathrm{a}, \mathrm{b}}$ \\
\hline $18: 0$ & $0 \cdot 28^{a, b}$ & $1.87^{\mathrm{a}}$ & $0.63^{a, b}$ & $-0.08^{a, b, c}$ & 0.42 & 0.07 & $0 \cdot 81^{\mathrm{a}, \mathrm{b}}$ & $0.48^{a, b}$ & $-0.03^{a, b, c, d}$ & $0.28^{\mathrm{a}}$ \\
\hline cis9-18:1 & $-0.02^{a, b, c}$ & $-0.25^{\mathrm{d}, \mathrm{e}, \mathrm{f}}$ & $-0.06^{a, b, c}$ & $-0.15^{\mathrm{a}, \mathrm{b}, \mathrm{c}, \mathrm{d}}$ & 0.00 & 0.24 & $0.01^{\mathrm{c}, \mathrm{d}}$ & $0.29^{a, b, c}$ & $-0.02^{a, b, c, d}$ & $0.25^{\mathrm{a}}$ \\
\hline trans $10-18: 1$ & $0.01^{\mathrm{a}, \mathrm{b}, \mathrm{c}}$ & $0.02^{\mathrm{c}, \mathrm{d}, \mathrm{e}}$ & $0.00^{\mathrm{a}, \mathrm{b}, \mathrm{c}}$ & $-0.01^{a, b}$ & 0.04 & 0.10 & $0 \cdot 17^{\mathrm{c}, \mathrm{d}}$ & $0.22^{b, c, d}$ & $-0 \cdot 18^{\mathrm{b}, \mathrm{c}, \mathrm{d}}$ & $-0.05^{a, b}$ \\
\hline trans $11-18: 1$ & $-0.09^{b, c}$ & $0.03^{\mathrm{c}, \mathrm{d}, \mathrm{e}}$ & $-0.29^{b, c}$ & $-0.02^{a, b}$ & 0.03 & 0.41 & $0.07^{\mathrm{c}, \mathrm{d}}$ & $0.26^{a, b, c}$ & $-0.18^{b, c, d}$ & $-0.37^{b}$ \\
\hline $18: 2$ & $0 \cdot 11^{a, b, c}$ & $-0.49^{e, f}$ & $0 \cdot 17^{\mathrm{a}, \mathrm{b}, \mathrm{c}}$ & $-0.09^{a, b, c, d}$ & 0.20 & 0.44 & $0 \cdot 14^{\mathrm{c}, \mathrm{d}}$ & $0.33^{a, b, c}$ & $0.05^{a, b, c}$ & $0.24^{a}$ \\
\hline cis9trans 11-18:2 & $0 \cdot 28^{a, b}$ & $0.36^{b, c, d}$ & $0 \cdot 71^{a}$ & $0 \cdot 10^{\mathrm{a}}$ & 0.44 & 0.46 & $0.30^{\mathrm{C}}$ & $0.69^{\mathrm{a}}$ & $0.11^{\mathrm{a}, \mathrm{b}}$ & $0.24^{\mathrm{a}}$ \\
\hline trans 10 cis $12-18: 2$ & $0.05^{a, b, c}$ & $-0.50^{e, f}$ & $0.08^{a, b, c}$ & $-0.19^{\mathrm{a}, \mathrm{b}, \mathrm{c}, \mathrm{d}}$ & -0.01 & 0.16 & $0.06^{\mathrm{c}, \mathrm{d}}$ & $0.37^{\mathrm{a}, \mathrm{b}, \mathrm{c}}$ & $0.04^{\mathrm{a}, \mathrm{b}, \mathrm{c}, \mathrm{d}}$ & $0.21^{a}$ \\
\hline $18: 3$ & $-0.21^{\mathrm{c}}$ & $-0.84^{f}$ & $-0.55^{c}$ & $-0.43^{\mathrm{d}, \mathrm{e}}$ & -0.17 & 0.27 & $0 \cdot 17^{\mathrm{c}, \mathrm{d}}$ & $0.23^{\mathrm{b}, \mathrm{c}}$ & $-0.23^{\mathrm{d}}$ & $-0.13^{a, b}$ \\
\hline $20: 0$ & $0.03^{a, b, c}$ & $0.11^{\mathrm{c}, \mathrm{d}, \mathrm{e}}$ & $-0.01^{a, b, c}$ & $-0.33^{\mathrm{c}, \mathrm{d}, \mathrm{e}}$ & -0.19 & 0.58 & $0.03^{\mathrm{c}, \mathrm{d}}$ & $0.02^{\mathrm{d}, \mathrm{c}}$ & $-0.06^{a, b, c, d}$ & $0.27^{\mathrm{a}}$ \\
\hline $20: 5$ & $0.02^{a, b, c}$ & $0.96^{\mathrm{b}}$ & $0.08^{a, b, c}$ & $-0.52^{\mathrm{e}}$ & -0.37 & 0.44 & $-0.16^{\mathrm{d}}$ & $-0.97^{d}$ & $0 \cdot 18^{\mathrm{a}}$ & $0 \cdot 14^{\mathrm{a}, \mathrm{b}}$ \\
\hline $22: 6$ & $0.19^{a, b, c}$ & $-0.06^{\mathrm{d}, \mathrm{e}}$ & $0 \cdot 25^{\mathrm{a}, \mathrm{b}, \mathrm{c}}$ & $-0.24^{\mathrm{b}, \mathrm{c}, \mathrm{d}, \mathrm{e}}$ & 0.05 & 0.36 & $0.20^{\mathrm{c}, \mathrm{d}}$ & $0.36^{a, b, c}$ & $0 \cdot 15^{a}$ & $0.28^{a}$ \\
\hline SEM & 0.09 & 0.14 & 0.18 & 0.06 & 0.18 & 0.12 & 0.09 & 0.08 & 0.05 & $0 \cdot 10$ \\
\hline
\end{tabular}

a,b,c,d,e,f Mean values within a row with unlike superscript letters were significantly different $(P<0.05$, Tukey's corrected).

ACOX1, acyl-coenzyme A oxidase 1; $A C S L 3,4,5$, and 6 , acyl-coenzyme A synthetase long-chain family member $3,4,5$ and $6 ; D B I$, diazepam binding inhibitor (GABA receptor modulator, acyl-coenzyme A binding protein); LPIN2 and 3, lipin 2 and 3; SOD1, superoxide dismutase 1, soluble; UCP2, uncoupling protein 2 (mitochondrial, proton carrier); CTR, control. 
Overall, our data confirm that MDBK, and by inference other bovine cells, respond to PPAR- $\alpha$ agonists and suggest, based on the thirty genes measured, a peculiar landscape in the transcriptomics response to WY in this species compared with non-ruminants. Even though the gene expression landscape was different between bovines and non-ruminants, the activation of PPAR- $\alpha$ appears to strongly control lipid metabolism as in non-ruminants.

\section{Long-chain fatty acids effect on PPAR $\alpha$ activation}

It has been well established in non-ruminants that PPAR are able to bind, and thus are activated by, LCFA. In addition, LCFA are capable of increasing the expression of PPARA, as has been shown by treatment of human hepatocytes with $150 \mu \mathrm{M}$ of $16: 0^{(40)}$. In non-ruminant species, unsaturated LCFA are more potent agonists of PPAR isotypes than saturated $\mathrm{LCFA}^{(41-43)}$. The larger degree of PPAR activation in rodents by polyunsaturated compared with saturated LCFA has been well established $^{(1)}$.
Our gene expression data (Figs. 1 and 2) summarised by the gene networks for each single LCFA treatment (Figs. 3- 5 and S10-S18 in additional file 1 , supplementary material for this article can be found at http://www.journals.cambridge.org/ bjn) suggested that all LCFA elicited their effects partly through the activation of PPAR $\alpha$ (i.e. up-regulated genes positively affected by WY). The same analyses support a greater degree of PPAR- $\alpha$ activation by saturated compared with unsaturated LCFA.

In the hierarchical clustering analysis considering data with statistical differences relative to CTR (Fig. 6), responses due to WY treatment clustered with all LCFA, particularly with saturated 16:0 and 18:0 (Fig. 6). Among all treatments EPA appeared to be the most different. The dendrogram (Fig. 6) highlighted both a remarkable similarity in effect among saturated LCFA on the measured genes and a clear separation with the unsaturated LCFA. In this regard, 20:0 was the LCFA with the most similar effect on the expression of the measured genes compared with unsaturated LCFA. Among the saturated LCFA, 16:0 and 18:0 clustered tightly together. The monounsaturated

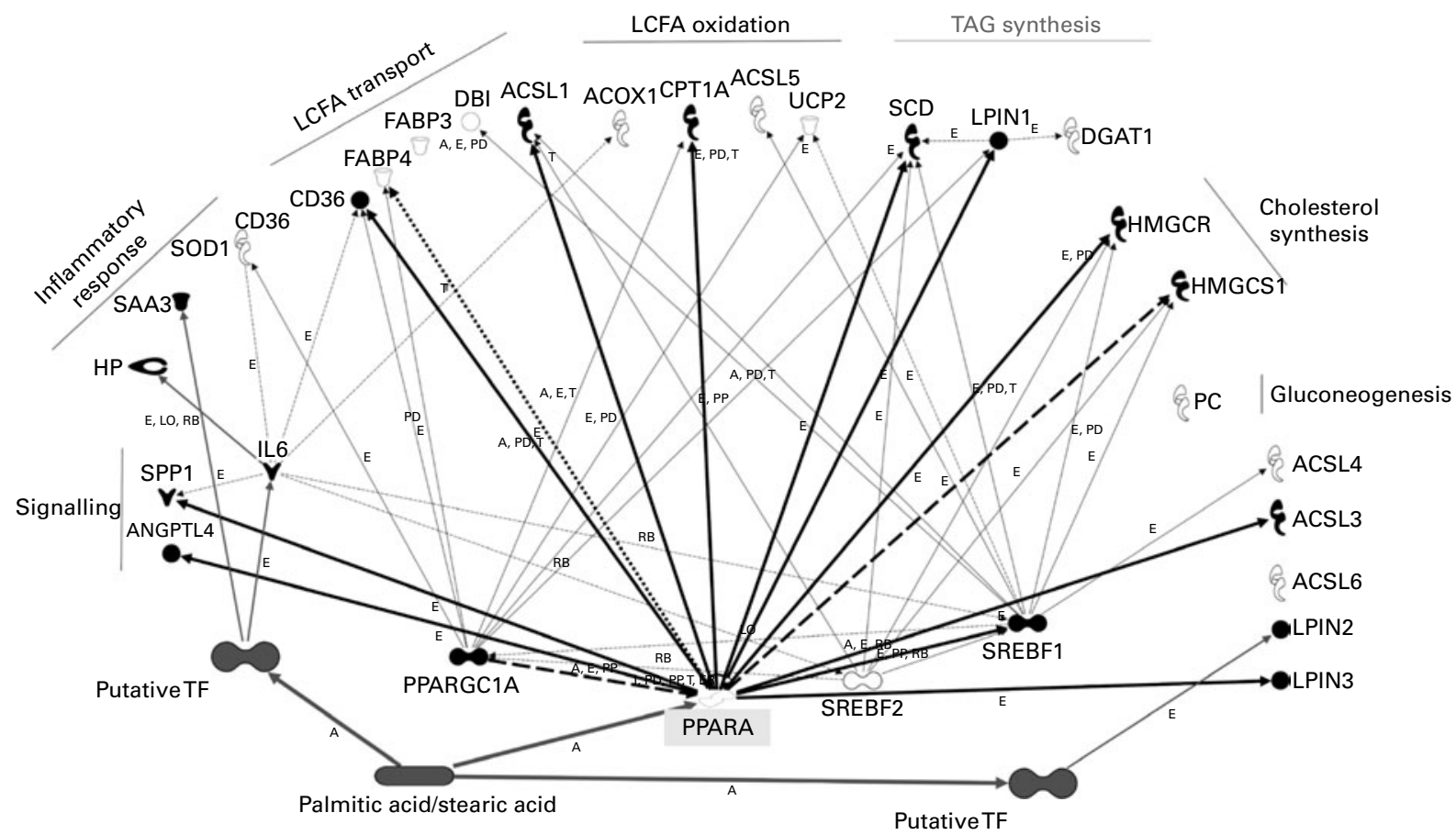

Fig. 4. Gene networks encompassing all genes measured that were affected by the saturated long-chain fatty acids (LCFA) 16:0 and 18:0. The expected biological outcome of those two LCFA considering the effect in expression of networks of genes measured would be an increase of lipid metabolism. This would occur by increasing uptake (CD36) and activation (ACSL1 and ACSL3) of LCFA, by increasing catabolism, particularly in the mitochondria through increase in LCFA transport (CPT1A), and anabolism, particularly synthesis of TAG (LPIN isoforms and SCD) and cholesterol (HMGCR and HMGCS1). Interestingly, the two saturated LCFA-activated expression of two transcription factors (TF) (PPARGC1A and SREBF1) involved in controlling expression of lipogenic genes and strongly activated expression of inflammatory response-related genes (IL6, SAA3, and HP) and signalling genes (SPP1 and ANGPTL4). The genes are denoted by objects and the letters along the arrows denote the type of effect (activation (A), effects on gene expression (E), protein-protein interactions (PP), protein-DNA interactions (PD), inhibition (I), RNA binding (RB), effect on translation ( $T$ ) and effect on localisation (LO)). Black objects fill denote up-regulation of the gene relative to control. Genes have been grouped based on main functions. The bolded black lines highlight the downstream targets genes of PPAR $\alpha$ (see Fig. 3). In dotted lines are highlighted genes responsive to Wy-14643 but not to 16:0 and 18:0. In dashed lines are highlighted non-ruminants PPAR $\alpha$ target genes which expression was up-regulated by 16:0 and 18:0 but not by Wy-14643 treatment. ANGPTL4, angiopoietin-like 4; SPP1, secreted phosphoprotein 1; HP, haptoglobin; SAA3, serum amyloid A 3; SOD1, superoxide dismutase 1; CD36, CD36 molecule; FABP3 and 4, fatty acid-binding protein 3 and 4; $D B I$, diazepam binding inhibitor; ACSL1, acyl-coenzyme A synthetase long-chain family member 1; ACOX1, acyl-coenzyme A oxidase 1; CPT1A, carnitine palmitoyltransferase 1A; ACSL3, 4, 5, and 6, acyl-coenzyme A synthetase long-chain family member 3, 4, 5 and 6; UCP2, uncoupling protein 2; SCD, stearoyl CoA desaturase; LPIN1, 2 and 3, lipin 1, 2 and 3; DGAT1, diacylglycerol-O-acyltransferase homolog 1; HMGCR, 3-hydroxy-3-methylglutaryl-coenzyme A reductase; HMGCS1, 3-hydroxy-3-methylglutarylcoenzyme A synthase 1; PC, pyruvate carboxylase; SREBF1 and 2, sterol regulatory element binding transcription factor 1 and 2; PPARA, PPAR alpha; PPARGC1A, PPAR gamma coactivator $1-\alpha$. 


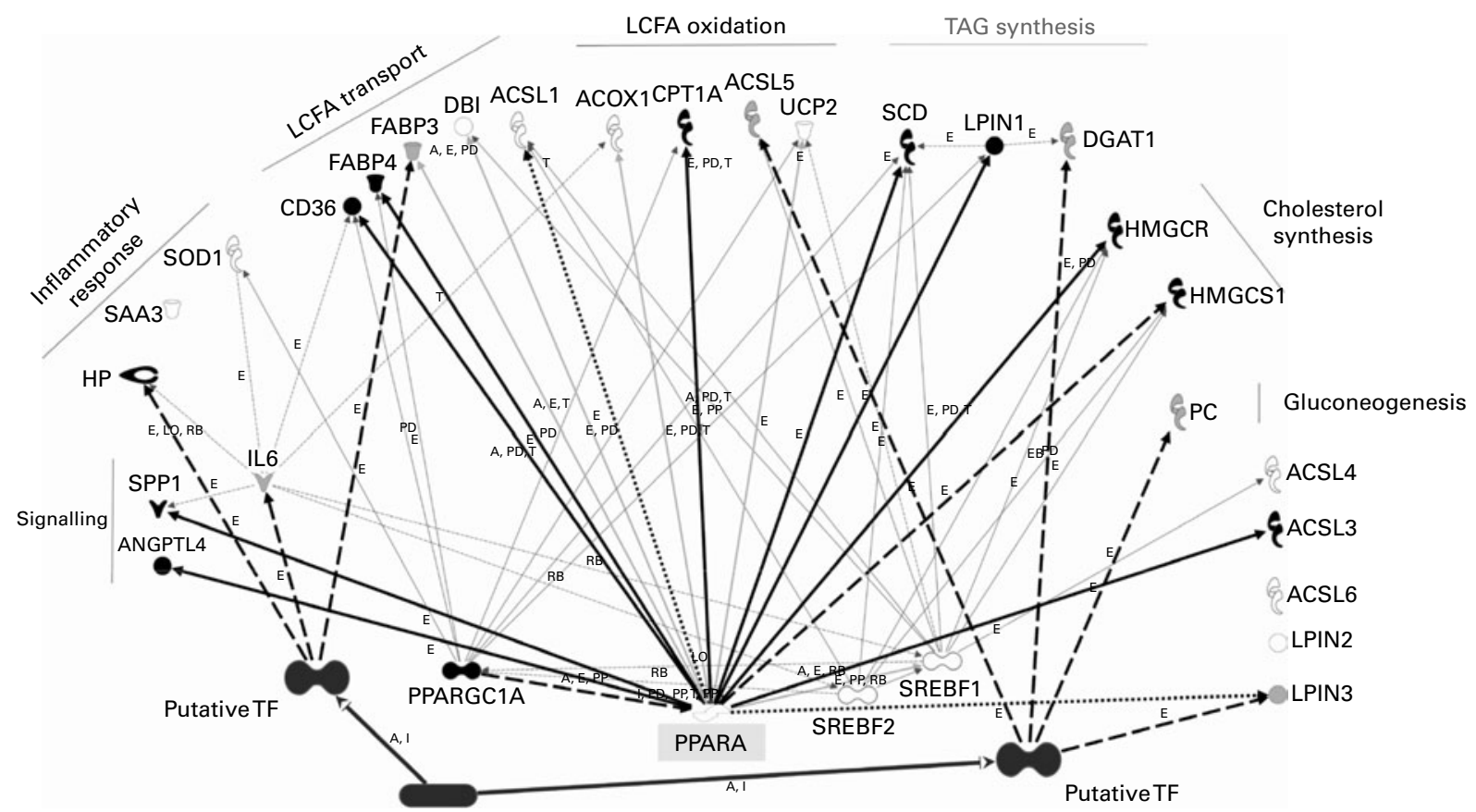

$5,8,11,14,17-\mathrm{EPA}$

Fig. 5. Gene networks encompassing all genes measured that were affected by EPA among all genes measured. The network analysis among measured genes indicated that treatment with EPA probably induced long-chain fatty acid (LCFA) oxidation in mitochondria, TAG and cholesterol synthesis, and production of signalling molecules; however, some of the genes involved in lipid metabolism were down-regulated (e.g. DGAT1 and ACSL5) as well PC and IL6, with a likely decrease in activation of IL6 network genes. In this regard, it was noteworthy the observed up-regulation of expression of $H P$, which probably indicates that expression of this gene was induced by EPA through a network not involving IL6. The genes are denoted by objects and the letters along the arrows denote the type of effect (activation (A), effects on gene expression (E), protein-protein interactions (PP), protein-DNA interactions (PD), inhibition (I), RNA binding (RB), effect on translation (T) and effect on localisation (LO)). Black objects fill denotes up-regulation and grey down-regulation of the gene relative to control. Genes have been grouped based on main functions. The bold lines highlight the downstream targets genes of PPAR $\alpha$ that overlap with genes up-regulated by EPA treatment (see Fig. 3). In dashed lines are highlighted genes affected by EPA probably through other (putative) transcription factors (TF), among those all except $H P$ were down-regulated and HMGCS1 was not up-regulated by Wy-14643 but was up-regulated by EPA treatment. The dotted lines highlighted the lack of effect of EPA on ACSL1 and LPIN3, the only ruminant-specific PPAR $\alpha$ target genes (see Fig. 3) no affected by EPA. ANGPTL4, angiopoietin-like 4; SPP1, secreted phosphoprotein 1; HP, haptoglobin; SAA3, serum amyloid A 3; SOD1, superoxide dismutase 1; CD36, CD36 molecule; FABP3 and 4, fatty acid-binding protein 3 and 4; $D B I$, diazepam binding inhibitor; $A C S L 1$, acyl-coenzyme A synthetase long-chain family member 1; ACOX1, acyl-coenzyme A oxidase 1; CPT1A, carnitine palmitoyltransferase 1A; $A C S L 3,4,5$, and 6, acyl-coenzyme A synthetase long-chain family member 3, 4, 5 and 6; UCP2, uncoupling protein 2; SCD, stearoyl CoA desaturase; LPIN1, 2 and 3, lipin 1, 2 and 3; DGAT1, diacylglycerol-O-acyltransferase homolog 1; HMGCR, 3-hydroxy-3-methylglutaryl-coenzyme A reductase; HMGCS1, 3-hydroxy-3-methylglutaryl-coenzyme A synthase 1; $P C$, pyruvate carboxylase; SREBF1 and 2, sterol regulatory element binding transcription factor 1 and 2; PPARA, PPAR alpha; PPARGC1A, PPAR gamma coactivator $1-\alpha$.

LCFA tended to cluster together as well as the nonconjugated and conjugated $18: 2$. The latter appeared to have an effect on the expression of the measured genes, which was more similar to saturated LCFA and WY than to the monounsaturated LCFA. Exogenous $c 9, t 11$-CLA clustered together with 20:0 and close to WY. Interestingly, if the cluster analysis was performed without considering the statistical difference in gene expression relative to CTR, exogenous WY did not cluster with the saturated LCFA (Fig. S19 in additional file 1, supplementary material for this article can be found at http://www.journals. cambridge.org/bjn) but, rather, with unsaturated LCFA and specifically with DHA. The correlation analysis (additional file 3, supplementary material for this article can be found at http://www.journals.cambridge.org/bjn) using both significant and non-significant outcomes seems to support a close relationship between WY and DHA. Even though the transcriptomics effect of all treatments correlated significantly, the lowest correlation was observed for 16:0 and 18:0 with other LCFA and WY. The clustering analysis among genes (Fig. 6) demonstrated a large similarity between the genes involved in
LCFA entry into cells (CD36) and into the mitochondria $(C P T 1 A)$. Interestingly, the two signalling molecules analysed (ANGPTL4 and SPP1) also tended to cluster together. No other functional clusters were observed among the measured genes.

The hierarchical clustering underscored that the response to palmitic and stearic acids in MDBK was very similar to WY, suggesting those LCFA being the more potent PPAR- $\alpha$ agonists among the one tested; however, the gene expression data (with the sole exception of FABP4 and ANGPTL4) showed a stronger response for nearly all the PPAR- $\alpha$ target genes measured with the two saturated LCFA compared with WY. It is noteworthy that the expression of HMGCS1, which is a known PPAR- $\alpha$ target in non-ruminants, was only numerically up-regulated by WY (i.e. it is a weak PPAR- $\alpha$ target in ruminants), but was significantly up-regulated in response to the two saturated LCFA (Fig. 2). The apparently greater potency of saturated LCFA, particularly 16:0, to activate PPAR- $\alpha$ in MDBK has also been observed previously ${ }^{(10,11)}$. Recently, we observed a larger response with saturated, namely 16:0, 


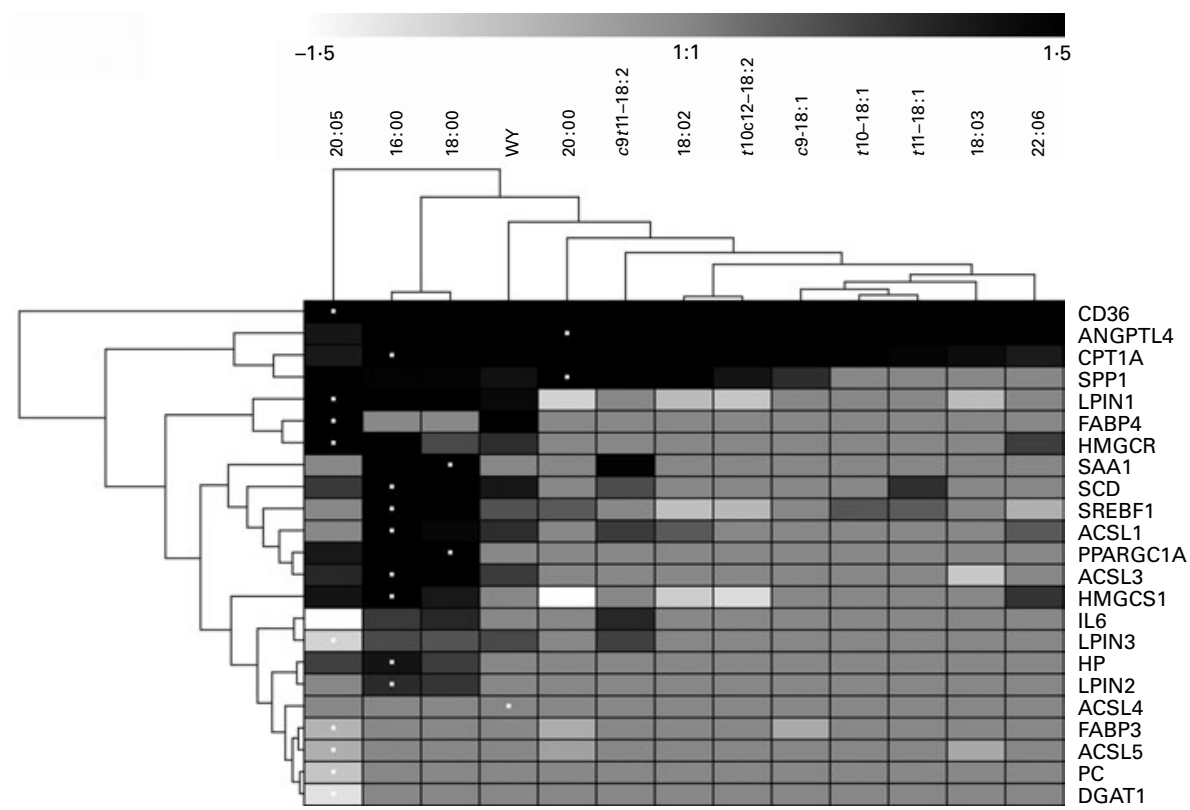

Fig. 6. Hierarchical clustering of gene expression data between treatments and between genes considering only data with significant differences relative to the control (CTR) using Genesis software ${ }^{(64)}$. Hierarchical cluster using all genes without considering the significance is reported in Fig. S19 in additional file 1 (supplementary material available online at http://www.journals.cambridge.org/bjn). The dendrogram allows visualisation of clusters of similarity in expression pattern between treatments (links denoted by the lines at the top of the figure) and between genes (links denoted by the lines at the left side of the picture). Log ${ }_{2}$ foldchange in expression relative to CTR are denoted by shades of black, increase; light grey-white, down-regulated; grey, no change relative to CTR according to the intensity bar at the top of the Fig. (refer to Table 1 and Figs. 1 and 2 for statistical differences). White dots denote the largest responses (up or down) in mRNA expression relative to CTR for each gene. CD36, CD36 molecule; ANGPTL4, angiopoietin-like 4; CPT1A, carnitine palmitoyltransferase 1A; SPP1, secreted phosphoprotein 1; $L P I N 1$, lipin 1; FABP 4, fatty acid-binding protein 4; HMGCR, 3-hydroxy-3-methylglutaryl-coenzyme A reductase; SAA1, serum amyloid A 1; SCD, stearoyl CoA desaturase; SREBF1, sterol regulatory element binding transcription factor 1; ACSL1, acyl-coenzyme A synthetase long-chain family member 1; PPARGC1A, PPAR gamma coactivator 1- $\alpha$; ACSL3, acyl-coenzyme A synthetase long-chain family member 3; HMGCS1, 3-hydroxy-3-methylglutaryl-coenzyme A synthase 1; LPIN3, lipin 3; HP, haptoglobin; LPIN2, lipin 2; ACSL4, acyl-coenzyme A synthetase long-chain family member 4; FABP3, fatty acid-binding protein 3; ACSL5, acyl-coenzyme A synthetase long-chain family member 5; $P C$, pyruvate carboxylase; DGAT1, diacylglycerol-O-acyltransferase homolog 1.

compared with a specific PPAR- $\gamma$ agonist in increasing the expression of several putative PPAR- $\gamma$ target genes in MacT cells ${ }^{(34)}$. From a physiological point of view, those data appear to highlight a teleological evolutionary adaptation of these nuclear receptors in ruminants to greater availability of saturated rather than unsaturated LCFA. The major LCFA in ruminant blood under most circumstances are palmitic, stearic and oleic $\operatorname{acid}^{(44)}$. In addition, the lower response of PPAR- $\alpha$ in MDBK to polyunsaturated LCFA, with the exception of EPA, is meaningful considering the large degree of ruminal biohydrogenation of those LCFA in bovine ${ }^{(45)}$. It is interesting from this point of view that, among unsaturated LCFA, the more potent activator of PPAR- $\alpha$ after EPA was $c 9, t 11$-CLA (Fig. S11 in additional file 1 , supplementary material for this article can be found at http://www.journals.cambridge.org/bjn), which can accumulate in the rumen due to unsaturated lipid feeding $^{(46)}$ or can be synthesised endogenously from vaccenic acid (another biohydrogenation intermediate) in tissues via the enzyme $\mathrm{SCD}^{(47)}$. This LCFA is one of the most abundant conjugated 18:2 in the blood of dairy cows ${ }^{(46)}$ and the most abundant CLA in ruminant milk and meat ${ }^{(47)}$.

The overall PPRE analysis (Table S7 in additional file 1, supplementary material for this article can be found at http:// www.journals.cambridge.org/bjn), but especially the correlation analysis between gene expression and the in silico PPRE binding strength (additional file 3, supplementary material for this article can be found at http://www.journals. cambridge.org/bjn), does not provide evidence of greater potential for LCFA in bovine to activate PPAR- $\gamma$ and PPAR- $\beta$ / $\delta$ compared with PPAR- $\alpha$. In non-ruminants, all three PPAR subtypes appear able to bind and be activated by LCFA ${ }^{(48)}$. Differences exist in non-ruminants in the binding capacity of the three PPAR isotypes, with $\alpha$ and $\beta / \delta$ being equally able to bind saturated and unsaturated LCFA while PPAR- $\gamma$ appears to be more prone to binding polyunsaturated LCFA ${ }^{(48)}$. The PPRE analysis of the three bovine PPAR isotypes seems to indicate that the LCFA could have increased/decreased expression of measured genes also through PPAR- $\gamma$. This was surmised because its PPRE is the most abundant in the genomic sequences of the genes analysed (Table S7 and Fig. S4 in additional file 1, supplementary material for this article can be found at http://www.journals.cambridge.org/bjn). In this regard, PPAR- $\beta / \delta$ appears to be a weaker player and our data do not support a strong functional overlap with PPAR- $\alpha$.

To evaluate the potential differences in LCFA binding in bovine cells, we have conducted an initial analysis of the three-dimensional structure of the ligand-binding domain of the three bovine PPAR isotypes (Fig. S20 in additional file 1, supplementary material for this article can be found at http://www.journals.cambridge.org/bjn) which does allow, with limitations, to make some inferences about the difference in binding capacity for LCFA between the three PPAR. In this 
regard, it was interesting from the three-dimensional images the apparent larger and more neutrally charged ligand pocket in PPAR- $\alpha$ compared with the other two PPAR isotypes, which is suggestive that it can accommodate larger and more neutral molecules (larger neutral carbon chain?) compared with other PPAR. The more negative charge in PPAR- $\gamma$ and the very large positive charge in PPAR- $\beta / \delta$ also emerged as interesting characteristics of the differences among PPAR isOtypes. As stated above, the in silico data have to be considered preliminary and in-depth molecular analyses (e.g. crystallography) are needed in order to uncover specific differences in the ligand-binding capacity between the three bovine PPAR isotypes.

\section{Gene networks affected by long-chain fatty acids}

Most of the measured genes, with the exception of $A C O X 1$, ACSL4, ACSL6, DBI, SOD1 and UCP2, were significantly affected after treatment with one or more LCFA (Figs. 1 and 2 and Table 1). The saturated LCFA appeared to have had a larger effect on the expression of the measured genes compared with unsaturated LCFA. The largest effect was observed for 16:0 and 18:0 (up-regulation of seventeen out of thirty measured transcripts or $56.7 \%$, Fig. 4) among the saturated (20: 0 affected $30 \%$ of genes, with four down-regulated, Fig. S10 in additional file 1, supplementary material for this article can be found at http://www.journals.cambridge.org/bjn) and EPA among the unsaturated LCFA (60\% measured transcripts affected, six genes down-regulated, Fig. 5). Among the other unsaturated LCFA, the effect on the expression of measured genes was $c 9, t 11$ CLA $\geq 18: 2>t 10, c 12$ CLA $=$ DHA $>>18: 3 \geq c 9-18: 1=t 11-\geq t 10-18: 1$ (Figs. S10-S18 in additional file 1 , supplementary material for this article can be found at http://www.journals.cambridge.org/bjn).

When considering the gene networks among the measured genes, all the LCFA tested appeared capable of eliciting oxidation of fatty acids ( $\Uparrow C D 36$ and $\Uparrow C P T 1 A$ ) and signalling through ANGPTL4 (summary in Figs. 4 and 5 and S10-S18 in additional file 1 , supplementary material for this article can be found at http://www.journals.cambridge.org/bjn). This general response was probably due to the fact that the culture media used was devoid of LCFA. Before starting the experiment, the MDBK cells were in the media with $10 \%$ fetal bovine serum containing approximately $0.015 \mathrm{mEq} / 1$ $\mathrm{NEFA}^{(11)}$. This was approximately 10 -fold less than the plasma NEFA concentration in bovines under normal conditions and approximately 50-fold less compared with cows just after parturition (see, for instance, Bionaz et al. ${ }^{(49)}$ ). Interestingly, CD36 and ANGPTL4 were the least abundant genes among all those measured in MDBK (Fig. S1 in additional file 1, supplementary material for this article can be found at http://www.journals.cambridge.org/bjn).

The effect on ANGPTL4 is of interest because this gene codes for a protein that is synthesised in several tissues including adipose and liver and seems to play roles within the liver and peripheral tissues including adipose ${ }^{(50)}$. For example, ANGPTL4 is up-regulated during fasting in bovines ${ }^{(51)}$ and non-ruminants ${ }^{(50)}$, and can bind and inactivate lipoprotein lipase in adipose tissue. An end-result of ANGPTL4 action is to increase plasma TAG and cholesteryl ester and decrease the uptake of fatty acids and cholesterol into peripheral tissues but, probably, increase availability of NEFA to the liver ${ }^{(50)}$. Interestingly, it was demonstrated recently that ANGPTL4 is up-regulated during the lipopolysacharide challenge in murine adipose, muscle and heart ${ }^{(52)}$. Thus, ANGPTL4 can be considered a novel positive acute-phase protein ${ }^{(52)}$. In the same study, the transcription of ANGPTL4 in the liver was down-regulated during the early response and upregulated during the late response to lipopolysacharide. In the present study, ANGPTL4 responded rapidly regardless of the type of LCFA treatment. We cannot exclude that in some of the treatments (e.g. saturated LCFA) ANGPTL4 responded as an acute-phase response molecule.

From an in vivo ruminant perspective, the responses in gene expression observed in the present study can be classified into two categories, those associated with the LCFA found primarily in the diet $(16: 0,18: 0, c 9-18: 1,18: 2$, 18:3, EPA and DHA) and those associated with ruminal metabolism ( $t 10-18: 1, t 11-18: 1, c 9, t 11$-CLA, $t 10, c 12-C L A$ and 20:0). An in-depth discussion of the gene networks affected by those categories of LCFA is reported in additional file 1 (supplementary material available online at http://www. journals.cambridge.org/bjn). In the following section, we briefly report the main findings within each category.

\section{Dietary long-chain fatty acids}

Among dietary LCFA, 16:0 and 18:0 and EPA elicited the largest changes in gene expression (Figs. 1 and 2). All three LCFA appear to have increased both catabolic and anabolic utilisation of LCFA (Figs. 4 and 5). Results for the saturated LCFA confirmed previous data obtained in hepatocytes from pre-ruminant calves ${ }^{(53)}$. Overall, the data indicated that saturated LCFA and EPA would increase uptake and utilisation of NEFA along with increased formation of cholesterol. The increase in cholesterol synthesis can be considered a positive outcome in bovine liver (and particularly in the peripartal period) because it is essential for the formation of lipoproteins to remove $\mathrm{TAG}^{(54)}$. The present and previous ${ }^{(53)}$ data appear to be supported by a recent in vivo study in which greater plasma cholesterol level was measured in late pregnant cows fed a palmitic acid-enriched diet ${ }^{(55)}$

The difference in the regulation of the expression of proinflammatory genes between the two saturated fatty acids and EPA was noteworthy (Fig. 2). The saturated LCFA elicited an evident increase in inflammation, at least considering the expression of the measured genes; EPA appeared to have reduced (mostly through $\Downarrow I L O$ ) inflammation. Although this represents the first evidence in bovine cells, judging from non-ruminant data, the decrease of inflammation by $\mathrm{EPA}^{(56)}$ and increase of inflammation by 16:0 are not entirely novel findings ${ }^{(57-59)}$. The inflammatory response induced by palmitate appears to occur through the activation of the NF-кB transcription factor, which, in turn, increases the expression of $I L 6^{(57-59)}$. In our case, the 'putative transcription factor(s)' 
reported in Fig. 4 could probably be NF-кB; however, this remains to be proven experimentally in bovines.

Even though PPARA was not up-regulated significantly by the dietary LCFA in the present study, up-regulation of its known co-activators, PPARGC1A ${ }^{(26)}$ and LPIN1 ${ }^{(19)}$, was substantial in response to 16:0, 18:0 and EPA (Figs. 1 and 2), suggesting that, besides activating PPAR- $\alpha$ through direct binding, those LCFA also increase its activation by enhancing the availability of co-activators. The other dietary LCFA ( $c 9$-18:1, $18: 2,18: 3$ and DHA) elicited only moderate effects on measured genes (Figs. 1 and 2 and S13-S15 in additional file 1 , supplementary material for this article can be found at http://www.journals.cambridge.org/bjn).

\section{Rumen-related long-chain fatty acids}

Far fewer changes were observed with LCFA that arise from ruminal metabolism (Figs. 1 and 2). Of all rumen-derived fatty acids investigated, 20:0 and c9,t11CLA elicited the most changes in gene expression (Figs. S10 and S11 in additional file 1 , supplementary material for this article can be found at http://www.journals.cambridge.org/bjn). Phytanic acid $(20: 0)$ is a branched-chained LCFA derived from the ruminal metabolism of chlorophyll ${ }^{(60)}$ and, as such, its production and deposition in tissues or milk is probably greater in cattle fed forage-based diets ${ }^{(61)}$. Phytanic acid is known to be a potent murine liver PPAR- $\alpha$ ligand $^{(13)}$ but also activates the other two PPAR isoforms, at least in the rat ${ }^{(62)}$. The effect of 20:0 on gene expression of measured genes suggested a reduced TAG and cholesterol synthesis in MDBK (Figs. S10 in additional file 1, supplementary material for this article can be found at http://www.journals.cambridge.org/bjn). To our knowledge, no previous bovine cell culture work has been carried out with 20:0, but in rat hepatocytes, it was demonstrated that it is involved in increasing glucose metabolism $^{(62)}$.

The functional responses of measured genes with exogenous $c 9, t 11$ CLA (or rumenic acid) as inferred by network analysis (Fig. S11, supplementary material for this article can be found at http://www.journals.cambridge.org/bjn) is partly consistent with previous findings. In fact, as all treatments in the present study, $c 9, t 11$ CLA increased the expression of genes associated with the oxidation of LCFA, which is commonly observed in rodents and humans fed with CLA ${ }^{(63)}$. The other rumen-related unsaturated LCFA had very modest effects on the expression of measured genes (Figs. 1 and 2 and summary in Figs. S12 and S16-S18 with discussion in additional file 1 , supplementary material for this article can be found at http://www.journals.cambridge.org/bjn).

In a recent study, we investigated the transcriptomics effect of several LCFA on MacT cells ${ }^{(34)}$. Several of those LCFA were also tested in the present study. To evaluate consistency in bovine cell responses to LCFA, we have conducted a comparison between the gene expression results between MDBK and MacT cells. The results are summarised in Table S10 (additional file 1 with therein relative discussion, available online at http://www.journals.cambridge.org/bjn). The analysis uncovered differences in response to LCFA between the two immortalised bovine cells, with a strikingly consistent greater response associated with saturated rather than unsaturated LCFA. The results from this comparison suggest caution when inferring data from one cell type to another; however, results support the fact that, opposite to non-ruminants, ruminant cells are more sensitive to saturated rather than unsaturated LCFA. The large response of bovine cells to PPAR agonists and LCFA strongly supports an effect of LCFA on the transcriptome.

\section{Conclusions}

The present study uncovered that ACSL1, ACSL3, ANGPTL4, CD36, CPT1A, FABP4, HMGCR, LPIN1, SCD and SREBF1, which are known PPAR- $\alpha$ targets in non-ruminants, are also induced by WY in the bovine. Novel and apparently bovinespecific PPAR- $\alpha$ targets were SPP1and LPIN3.

Our data provided potential avenues for the future, and more oriented, experiments in order to test the feasibility of using dietary LCFA to finely modulate metabolism in ruminant tissues such as the liver. The present study provides support for several LCFA as being PPAR- $\alpha$ agonists (particularly 16:0, 18:0 and EPA), but additional studies should be conducted to examine with greater confidence the binding and potency of activation of PPAR- $\alpha$ by LCFA, e.g. studies using the same experimental design but with the use of PPAR- $\alpha$ antagonists or the inhibition of PPAR- $\alpha$ expression/translation (e.g. by using siRNA).

In conclusion, the results from the present study strongly support the possibility that dietary LCFA, and particularly 16:0 and 18:0, are able to modulate ruminant metabolism, particularly lipid metabolism, with the major effects probably induced via the activation of PPAR. Those findings need to be verified in an in vivo milieu with the exciting possibility that, if verified, they will open novel opportunities for fine-tuning the regulation of bovine metabolism via careful/controlled dietary approaches. Those could have a tremendous impact in the dairy industry, for example, by providing the means to prevent metabolic disorders such as fatty liver.

\section{Acknowledgements}

We gratefully acknowledge funding from National Institute of Food and Agriculture (Washington, DC, USA) under projects ILLU-538-952 and ILLU-538-961. M. B. and J. J. L. conceived and designed the study. As part of the MS thesis B. J. T. coordinated and performed the study and qPCR analysis, and conducted the initial statistical analysis of $\mathrm{qPCR}$ data. M. B. helped perform and coordinate the study, performed final statistical analysis of the qPCR data, performed the PPRE and three-dimensional analyses, prepared the figures, and wrote the manuscript. J. J. L. supervised all aspects of the study and helped write the final manuscript. All authors read and approved the final manuscript. There are no financial or other contractual agreements that might cause conflict of interests. 


\section{References}

1. Bragt MC \& Popeijus HE (2008) Peroxisome proliferatoractivated receptors and the metabolic syndrome. Physiol Behav 94, 187-197.

2. Kumamoto T \& Ide T (1998) Comparative effects of alphaand gamma-linolenic acids on rat liver fatty acid oxidation. Lipids 33, 647-654.

3. Desvergne B, Michalik L \& Wahli W (2006) Transcriptional regulation of metabolism. Physiol Rev 86, 465-514.

4. Jay MA \& Ren J (2007) Peroxisome proliferator-activated receptor (PPAR) in metabolic syndrome and type 2 diabetes mellitus. Curr Diabetes Rev 3, 33-39.

5. Kim MS, Sweeney TR, Shigenaga JK, et al. (2007) Tumor necrosis factor and interleukin 1 decrease RXRalpha, PPARalpha, PPARgamma, LXRalpha, and the coactivators SRC-1, PGC-1alpha, and PGC-1beta in liver cells. Metabolism 56, 267-279.

6. Zandbergen F \& Plutzky J (2007) PPARalpha in atherosclerosis and inflammation. Biochim Biophys Acta 1771, 972-982.

7. Drackley JK (1999) ADSA Foundation Scholar Award. Biology of dairy cows during the transition period: the final frontier? J Dairy Sci 82, 2259-2273.

8. Loor JJ, Dann HM, Everts RE, et al. (2005) Temporal gene expression profiling of liver from periparturient dairy cows reveals complex adaptive mechanisms in hepatic function. Physiol Genomics 23, 217-226.

9. Selberg KT, Staples CR, Luchini ND, et al. (2005) Dietary trans octadecenoic acids upregulate the liver gene encoding peroxisome proliferator-activated receptor-alpha in transition dairy cows. J Dairy Res 72, 107-114.

10. Bionaz M, Baumrucker CR, Shirk E, et al. (2008) Characterization of madin-darby bovine kidney cell line for peroxisome proliferator-activated receptors: temporal response and sensitivity to fatty acids. J Dairy Sci 91, 2808-2813.

11. Thering BJ, Bionaz M \& Loor JJ (2009) Long-chain fatty acid effects on peroxisome proliferator-activated receptoralpha-regulated genes in Madin-Darby bovine kidney cells: optimization of culture conditions using palmitate. J Dairy Sci 92, 2027-2037.

12. Litherland NB, Wallace RL, Bionaz M, et al. (2010) Effects of peroxisome proliferator activated receptor- $\alpha$ agonists clofibrate and fish oil on liver fatty acid metabolism in weaned dairy calves. J Dairy Sci 93, 2404-2418.

13. Wolfrum C, Borrmann CM, Borchers T, et al. (2001) Fatty acids and hypolipidemic drugs regulate peroxisome proliferator-activated receptors alpha- and gamma-mediated gene expression via liver fatty acid binding protein: a signaling path to the nucleus. Proc Natl Acad Sci U S A 98, 2323-2328.

14. Goya K, Sumitani S, Xu X, et al. (2004) Peroxisome proliferatoractivated receptor alpha agonists increase nitric oxide synthase expression in vascular endothelial cells. Arterioscler Thromb Vasc Biol 24, 658-663.

15. Hayashida K, Kume N, Minami M, et al. (2004) Peroxisome proliferator-activated receptor alpha ligands activate transcription of lectin-like oxidized low density lipoprotein receptor-1 gene through GC box motif. Biochem Biophys Res Commun 323, 1116-1123.

16. Bionaz M \& Loor JJ (2008) Gene networks driving bovine milk fat synthesis during the lactation cycle. BMC Genomics 9, 366.

17. Durgan DJ, Smith JK, Hotze MA, et al. (2006) Distinct transcriptional regulation of long-chain acyl-CoA synthetase isoforms and cytosolic thioesterase 1 in the rodent heart by fatty acids and insulin. Am J Physiol Heart Circ Physiol 290, H2480-H2497.

18. Phan J, Peterfy M \& Reue K (2004) Lipin expression preceding peroxisome proliferator-activated receptor-gamma is critical for adipogenesis in vivo and in vitro. $J$ Biol Chem 279, 29558-29564.

19. Finck BN, Gropler MC, Chen Z, et al. (2006) Lipin 1 is an inducible amplifier of the hepatic PGC-1alpha/PPARalpha regulatory pathway. Cell Metab 4, 199-210.

20. Lefever S, Hellemans J, Pattyn F, et al. (2009) RDML: structured language and reporting guidelines for real-time quantitative PCR data. Nucleic Acids Res 37, 2065-2069.

21. Bustin SA, Benes V, Garson JA, et al. (2009) The MIQE guidelines: minimum information for publication of quantitative real-time PCR experiments. Clin Chem 55, 611-622.

22. Heinaniemi M, Uski JO, Degenhardt T, et al. (2007) Meta-analysis of primary target genes of peroxisome proliferator-activated receptors. Genome Biol 8, R147.

23. Guex N \& Peitsch MC (1997) SWISS-MODEL and the Swiss-PdbViewer: an environment for comparative protein modeling. Electrophoresis 18, 2714-2723.

24. Rakhshandehroo M, Hooiveld G, Müller M, et al. (2009) Comparative analysis of gene regulation by the transcription factor PPAR $\alpha$ between mouse and human. PLoS One 4 , e6796.

25. Lehmann JM, Lenhard JM, Oliver BB, et al. (1997) Peroxisome proliferator-activated receptors alpha and gamma are activated by indomethacin and other non-steroidal anti-inflammatory drugs. J Biol Chem 272, 3406-3410.

26. Mandard S, Muller M \& Kersten S (2004) Peroxisome proliferator-activated receptor alpha target genes. Cell Mol Life Sci 61, 393-416

27. Tamura K, Ono A, Miyagishima T, et al. (2006) Profiling of gene expression in rat liver and rat primary cultured hepatocytes treated with peroxisome proliferators. $J$ Toxicol Sci 31, 471-490.

28. van der Meer DL, Degenhardt T, Vaisanen S, et al. (2010) Profiling of promoter occupancy by PPAR\{alpha\} in human hepatoma cells via ChIP-chip analysis. Nucleic Acids Res 38, 2839-2850.

29. Pineda Torra I, Jamshidi Y, Flavell DM, et al. (2002) Characterization of the human PPARalpha promoter: identification of a functional nuclear receptor response element. Mol Endocrinol 16, 1013-1028.

30. Reue K \& Zhang P (2008) The lipin protein family: dual roles in lipid biosynthesis and gene expression. FEBS Lett $\mathbf{5 8 2}$, 90-96.

31. Wang Y, Botolin D, Xu J, et al. (2006) Regulation of hepatic fatty acid elongase and desaturase expression in diabetes and obesity. J Lipid Res 47, 2028-2041.

32. Morandini P, Salamini F \& Gantet P (2005) Engineering of plant metabolism for drug and food. Curr Med Chem Immunol Endocr Metab Agents 5, 103-112.

33. Horton JD (2002) Sterol regulatory element-binding proteins: transcriptional activators of lipid synthesis. Biochem SOC Trans 30, 1091-1095.

34. Kadegowda AK, Bionaz M, Piperova LS, et al. (2009) Peroxisome proliferator-activated receptor-gamma activation and long-chain fatty acids alter lipogenic gene networks in bovine mammary epithelial cells to various extents. J Dairy Sci 92, 4276-4289.

35. Lambe KG, Woodyatt NJ, Macdonald N, et al. (1999) Species differences in sequence and activity of the peroxisome proliferator response element (PPRE) within the acyl CoA oxidase gene promoter. Toxicol Lett 110, 119-127. 
36. Rodriguez C, Noe V, Cabrero A, et al. (2000) Differences in the formation of PPARalpha-RXR/acoPPRE complexes between responsive and nonresponsive species upon fibrate administration. Mol Pharmacol 58, 185-193.

37. Lee JH, Banerjee A, Ueno Y, et al. (2008) Potential relationship between hepatobiliary osteopontin and peroxisome proliferator-activated receptor alpha expression following ethanol-associated hepatic injury in vivo and in vitro. Toxicol Sci 106, 290-299.

38. Oyama Y, Akuzawa N, Nagai R, et al. (2002) PPARgamma ligand inhibits osteopontin gene expression through interference with binding of nuclear factors to $\mathrm{A} / \mathrm{T}$-rich sequence in THP-1 cells. Circ Res 90, 348-355.

39. Forman BM, Tontonoz P, Chen J, et al. (1995) 15-Deoxydelta 12, 14-prostaglandin $\mathrm{J} 2$ is a ligand for the adipocyte determination factor PPAR gamma. Cell 83, 803-812.

40. Swagell CD, Henly DC \& Morris CP (2007) Regulation of human hepatocyte gene expression by fatty acids. Biochem Biophys Res Commun 362, 374-380.

41. Kliewer SA, Sundseth SS, Jones SA, et al. (1997) Fatty acids and eicosanoids regulate gene expression through direct interactions with peroxisome proliferator-activated receptors alpha and gamma. Proc Natl Acad Sci U S A 94, 4318-4323.

42. Desvergne B \& Wahli W (1999) Peroxisome proliferatoractivated receptors: nuclear control of metabolism. Endocr Rev 20, 649-688.

43. Larter CZ (2007) Not all models of fatty liver are created equal: understanding mechanisms of steatosis development is important. J Gastroenterol Hepatol 22, 1353-1354.

44. Leroy JL, Vanholder T, Mateusen B, et al. (2005) Nonesterified fatty acids in follicular fluid of dairy cows and their effect on developmental capacity of bovine oocytes in vitro. Reproduction 130, 485-495.

45. Hess BW, Moss GE \& Rule DC (2008) A decade of developments in the area of fat supplementation research with beef cattle and sheep. J Anim Sci 86, E188-E204.

46. Loor JJ, Ferlay A, Ollier A, et al. (2005) High-concentrate diets and polyunsaturated oils alter trans and conjugated isomers in bovine rumen, blood, and milk. J Dairy Sci $\mathbf{8 8}$, 3986-3999.

47. Dhiman TR, Nam SH \& Ure AL (2005) Factors affecting conjugated linoleic acid content in milk and meat. Crit Rev Food Sci Nutr 45, 463-482.

48. Grimaldi PA (2007) Peroxisome proliferator-activated receptors as sensors of fatty acids and derivatives. Cell Mol Life Sci 64, 2459-2464.

49. Bionaz M, Trevisi E, Calamari L, et al. (2007) Plasma paraoxonase, health, inflammatory conditions, and liver function in transition dairy cows. J Dairy Sci 90, 1740-1750.
50. Lichtenstein L \& Kersten S (2010) Modulation of plasma TG lipolysis by Angiopoietin-like proteins and GPIHBP1. Biochim Biophys Acta 1801, 415-420.

51. Loor JJ, Everts RE, Bionaz M, et al. (2007) Nutrition-induced ketosis alters metabolic and signaling gene networks in liver of periparturient dairy cows. Physiol Genomics 32, 105-116.

52. Lu B, Moser A, Shigenaga JK, et al. (2010) The acute phase response stimulates the expression of angiopoietin like protein 4. Biochem Biophys Res Commun 391, 1737-1741.

53. Mashek DG \& Grummer RR (2003) Effects of long chain fatty acids on lipid and glucose metabolism in monolayer cultures of bovine hepatocytes. J Dairy Sci 86, 2390-2396.

54. Hocquette JF \& Bauchart D (1999) Intestinal absorption, blood transport and hepatic and muscle metabolism of fatty acids in preruminant and ruminant animals. Reprod Nutr Dev 39, 27-48.

55. Andersen JB, Ridder C \& Larsen T (2008) Priming the cow for mobilization in the periparturient period: effects of supplementing the dry cow with saturated fat or linseed. J Dairy Sci 91, 1029-1043.

56. Soumura M, Kume S, Isshiki K, et al. (2010) Oleate and eicosapentaenoic acid attenuate palmitate-induced inflammation and apoptosis in renal proximal tubular cell. Biochem Biophys Res Commun 402, 265-271.

57. Ajuwon KM \& Spurlock ME (2005) Palmitate activates the NF-kappaB transcription factor and induces IL-6 and TNFalpha expression in 3T3-L1 adipocytes. J Nutr 135, 1841-1846.

58. Ciapaite J, van Bezu J, van Eikenhorst G, et al. (2007) Palmitate and oleate have distinct effects on the inflammatory phenotype of human endothelial cells. Biochim Biophys Acta 1771, 147-154.

59. Coll T, Eyre E, Rodriguez-Calvo R, et al. (2008) Oleate reverses palmitate-induced insulin resistance and inflammation in skeletal muscle cells. $J$ Biol Chem 283 11107-11116

60. Dawson RM, Hemington N, Grime D, et al. (1974) Lipolysis and hydrogenation of galactolipids and the accumulation of phytanic acid in the rumen. Biochem J 144, 169-171.

61. Lee MR, Connelly PL, Tweed JK, et al. (2006) Effects of highsugar ryegrass silage and mixtures with red clover silage on ruminant digestion. 2. Lipids. J Anim Sci 84, 3061-3070.

62. Heim M, Johnson J, Boess F, et al. (2002) Phytanic acid, a natural peroxisome proliferator-activated receptor (PPAR) agonist, regulates glucose metabolism in rat primary hepatocytes. FASEB J 16, 718-720.

63. DeLany JP \& West DB (2000) Changes in body composition with conjugated linoleic acid. J Am Coll Nutr 19, 487S-493S.

64. Sturn A, Quackenbush J \& Trajanoski Z (2002) Genesis: cluster analysis of microarray data. Bioinformatics 18, 207-208. 